\title{
Condylar Morphology- A Review
}

\author{
Durgha.K. \\ Saveetha Dental College, Chennai. India.
}

\begin{abstract}
The temporomandibular joint is a complex joint, the components of which are enclosed within a capsule and stabilized by ligaments. The various movements that occur at the TMJ are possible due to the coordinated action between the various muscles, ligaments and the associated movements that occur in the condyle. Condylar morphology is assessed using radiographic methods and the various factors that influence morphology of the condyle were traced out.. The purpose of this review is to provide an insight about the various factors that influence condylar morphology.
\end{abstract}

\section{Introduction}

The tempromandibular joint is a ginglymo-diarthroidal joint which consists of the glenoid fossa, the mandibular condyle and the articular disc which are enclosed within a fibrous capsule and the joint is stabilized by the extracapsular tempromandibular and sphenomandibular ligament ${ }^{[1,2]}$. The TMJ is capable of producing a variety of movements like opening, closing, lateral and translatory movements ${ }^{[2]}$. This is possible due to the coordination between the various muscles, ligaments and the associated movements of the condyle. The human condyle has a capacity for remodelling ${ }^{[3]}$ which are influenced by a variety of factors which can result in morphological diversity and variations in shape. Several studies have dealt with the position of the condyle but not much emphasis has been laid on the shape of the condyle ${ }^{[4]}$

In this review the various factors which influence the morphology of the condyle are discussed.

The radiographic tools used in the assessment of condylar morphology are Computed Tomogram $(\mathrm{CT})^{[4,5]}$, Cone Beam Computed Tomography $(\mathrm{CBCT})^{[6,7]}$, Orthopantomogram $(\mathrm{OPG})^{[8]}$ and Lateral Cephalogram ${ }^{[4,9]}$.

\section{A Review}

Age:

Age is a factor that determines the degree of remodeling, though there is no direct linear relationship ${ }^{[8]}$. Because the adaptive or degenerative changes in the temporomandibular joints appear over a long period of time, it is understandable that the condylar changes increase with advancing age ${ }^{[10,11,12]}$. The prevalence of changes in the condylar morphology as assessed by orthopantomogram was found to be relatively lower in subjects who were between 20-40years of age as compared to those above 40 years. Whereas flattening, erosion, and sclerosis were observed more commonly in the older age group as compared to the younger age group but the prevelance of osteophyte and ely's cyst decreased as age advances ${ }^{[8]}$

Sex:

The condylar surface area as well as volume as assessed using CBCT was significantly higher in males than in females ${ }^{[7,13]}$. Morphological index which is indicated as a ratio between surface and volume shows the difference between females and males is about $2.8 \%$ of the $\mathrm{MI}$ in the whole sample ${ }^{[7]}$. Both the volume and the area of a condyle differ between the genders and the subjects with different skeletal class ${ }^{[14]}$. The linear measurements showed that the anteroposterior dimension of the condyle had a mean value of 8.25 for females and $8.42 \mathrm{~mm}$ for males. The mediolateral dimension of the condyle showed a mean value of $18.92 \mathrm{~mm}$ for females and $18.98 \mathrm{~mm}$ for males, with no statistically significant differences between sexes for the anteroposterior or mediolateral dimensions of the condyle ${ }^{[9]}$. Christiansen and Thompson (1990) also reported that the transverse condylar dimension of normal adult joints was greater for men $(19.6 \mathrm{~mm})$ than for women $(17.7 \mathrm{~mm})^{[15]}$

\section{Shape:}

Studies conducted on condylar morphology in dry skulls using x-ray imaging revealed that condyles that had a superior convex surface and oval form were observed frequently ${ }^{[16]}$. Radiographic analysis showed that in the anterior view, $58.4 \%$ of the specimens exhibited a plane or slightly convex shape, $25 \%$ a wellrounded or convex shape, $16.6 \%$ were shaped like an inverted "V", and only $3.1 \%$ were convex. In the upper view, many of the condyles $(60 \%)$ had an oblong shape, $20 \%$ were pear-shaped and laterally tapered, $18.4 \%$ were pear-shaped but medially tapered, and only $1.6 \%$ had a rounded or oval shape. Of the skulls examined in 
the lateral view, 55\% were pointy or shaped like an inverted "V", $31.7 \%$ had a convex shape, and $13.3 \%$ were plane or slightly convex ${ }^{[9]}$

\section{Occlusal force:}

Earlier it was thought that the compressive stresses that were generated during clenching was localized at the lateral surface of the condyle by the distribution of sulfated glycosaminoglycan ${ }^{[17]}$.Recent finite-element analysis reveales that the largest stress is generated at the middle-to-lateral and superior-to-posterior areas of the condylar cartilage during jaw closure ${ }^{[18]}$. Occlusal force is one of the important factors influencing maxillofacial development. Occlusal force, maxillofacial morphology, and mandibular condyle morphology seem to influence each other, but the relationship between occlusal force and mandibular condyle morphology has not been reported The high-occlusal-force group tended to have condyles with larger, more rounded form at the lateral and posterior side than the low-occlusal-force group ${ }^{[6]}$. But a particular study showed no significant correlation between condyle shape and occlusal characteristics ${ }^{[9]}$. An increase in the function of the masticatory muscles is associated with anterior growth rotation pattern of the mandible and with well-developed angular, coronoid, and condylar processes ${ }^{[19]}$.

\section{Malocclusion:}

Examination using lateral cephalograms shows no condylar shape difference between class II and class III malocclusion ${ }^{[20]}$. The condylar morphology assessed using 3DX imaging revealed that condyles of class II patients were smaller than the condyles of patients with class I malocclusion ${ }^{[6]}$. The mean anteroposterior thickness of condylar head as assessed using CT was 8.13 and $8.42 \mathrm{~mm}$ for left and right sides, respectively, for class I normal occlusion and 7.25 and $7.39 \mathrm{~mm}$ for left and right sides, respectively, for class II division 1 malocclusion $^{[5]}$

\section{Skeletal class:}

TMJ morphology has a strong correlation with skeletal morphology ${ }^{[21]}$ and exclusively an inverse relationship between the angle of the articular eminence and the occlusal and the mandibular planes ${ }^{[22]}$. Mongini $^{[23]}$ reported a correlation between condylar shape and its position in the fossa which was confirmed by Akahane et al ${ }^{[24]}$.

Skeletal class III pattern was more closely associated with the asymmetry of condylar inclination than skeletal I and II groups ${ }^{[25-27]}$. In a study in which condylar volume was calculated using 3D CBCT showed that greater condylar volume was associated with skeletal class III ${ }^{[7]}$.

\section{Conclusion:}

- As the age increased there is a significant increase in the number of condyles affected.

- Both the volume and the area of a condyle differ between the genders.

- Occlusal force, maxillofacial morphology, and mandibular condyle morphology seem to influence each other.

- An increase in the function of the masticatory muscles is associated with anterior growth rotation pattern of the mandible and with well-developed angular, coronoid, and condylar processes.

- TMJ morphology has a strong correlation with skeletal morphology and exclusively an inverse relationship between the angle of the articular eminence and the occlusal and the mandibular planes.

\section{Acknowledgement}

I would like to express my special thanks of gratitude to my teacher who gave me the golden opportunity to do this wonderful project on the topic 'Condylar morphology - a review' with which I came to know about so many new things. Secondly I would also like to thank my parents and friends who helped me a lot in putting this review together within the limited time frame.

\section{References}

[1]. Neelima anil malik. Textbook of oral and maxillofacial surgery. $2^{\text {nd }}$ edition.India: Jaypee brothers, medical publishers(p) ltd.2008. Print.

[2]. SM Balaji. Textbook of oral and maxillofacial surgery.

[3]. Zarb GA, Carlsson GE. Osteoarthrosis/osteoarthritis. In: Zarb GE, Carlsson GE, Sessle BJ, Mohl ND(eds). Tempromandibular joint and Masticatory Muscle Disorders. Copenhagen: Munksgaard, 1994: 298-314

[4]. Elias G. Katsavrias and Demetrios J. Halazonetis. Condyle and fossa shape in Class II and Class III skeletal patterns: A morphometric tomographic study. American Journal of Orthodontics \& Dentofacial Orthopedics 2005;128:337-46

[5]. K. C. Prabhat, Sanjeev Kumar Verma,Sandhya Maheshwari, Ibne Ahmad and Mohd. Tariq. Computed Tomography Evaluation of Craniomandibular Articulation in Class II Division 1 Malocclusion and Class I Normal Occlusion Subjects in North Indian Population. ISRN Dentistry. Volume 2012. Article ID 312031,5 pages. doi:10.5402/2012/312031 
[6]. Aya Kurusu, Mariko Horiuchi, and Kunimichi Soma. Relationship between Occlusal Force and Mandibular Condyle Morphology Evaluated by Limited Cone-Beam Computed Tomography. The Angle Orthodontist: November 2009, Vol. 79, No. 6, pp. 10631069.

[7]. Matteo Saccucci, Michele D'Attilio, Daria Rodolfino, Felice Festa, Antonella Polimeni and Simona Tecco. Condylar volume and condylar area in class I, class II and class III young adult subjects. Head \& Face Medicine 2012, 8:34 doi:10.1186/1746-160X-8-34

[8]. Anuna Laila Mathew, Amar A. Sholapurkar,and Keerthilatha M. Pai. Condylar Changes and Its Association with Age, TMD, and Dentition Status: A Cross-Sectional Study. International Journal of Dentistry. Volume 2011. Article ID 413639, 7 pages doi: $10.1155 / 2011 / 413639$

[9]. Matsumoto MA, Bolognese AM. Bone morphology of the temporomandibular joint and its relation to dental occlusion. Braz Dent J. 1995;6(2):115-22

[10]. Y. Takayama, E. Miura, M. Yuasa, K. Kobayashi, and T. Hosoi, "Comparison of occlusal condition and prevalence of bone change in the condyle of patients with and without temporomandibular disorders," Oral Surgery, Oral Medicine, Oral Pathology, Oral Radiology and Endodontology, vol. 105, no. 1, pp. 104-112, 2008.

[11]. H. Sato, T. Österberg, M. Ahlqwist, G. E. Carlsson, H. G. Gröndahl, and B. Rubinstein, "Association between radiographic findings in the mandibular condyle and temporomandibular dysfunction in an elderly population," Acta Odontologica Scandinavica, vol. 54, no. 6, pp. 384-390, 1996

[12]. K. Hiltunen, M. M. Vehkalahti, J. S. Peltola, and A. Ainamo, "A 5-year follow-up of occlusal status and radiographic findings in mandibular condyles of the elderly," International Journal of Prosthodontics, vol. 15, no. 6, pp. 539-543, 2002

[13]. Song WC: Female-to-male proportions of the head and face in Koreans. J Craniofac Surg 2009, 20:356-361.

[14]. Willems NMBK, et al.: Age-related changes in microarchitecture and mineralization of cancellous bone in the porcine mandibular condyle. J Struct Biol 2007, 158:421-427

[15]. Christiansen EL, Thompson JR: Temporomandibular joint imaging. Mosby Co., St. Louis 5-26, 1990

[16]. Yale, S. H. , B. D. Allison, and J. D. Hauptfuehrer . An epidemiological assessment of mandibular condyle morphology. Oral Surg Oral Med Oral Pathol 1996. 21:169-177.

[17]. Kopp, S. Topographical distribution of sulfated glycosaminoglycans in the surface layers of the human temporomandibular joint. J Oral Pathol 1978. 7:283-294.

[18]. Koolstra, J. H. and T. M. van Eijden . Combined finite-element and rigid-body analysis of human jaw joint dynamics. J Biomech2005. 38:2431-2439.

[19]. Stavros Kiliaridis. Masticatory muscle influence on craniofacial growth. Informa health care. 1995,53(3)196-202.

[20]. Burke G, Major P, Glover K, Prasad N. Correlations between condylar characteristics and facial morphology in class II preadolescent patients. Am J Orthod Dentofacial Orthop. 1998; 114:328-36

[21]. Widman DJ: Functional and morphologic considerations of the articular eminence. Angle Orthodontics 1988, 58:221-236.

[22]. Yamaki M, et al.: The relationship between mandibular movement and dentofacial morphology: a preliminary report. Nihon Ago Kansetsu Gakkai Zasshi (Journal of Japanese Society for Temporomandibular Joint) 1990, 2:22-33.

[23]. Mongini F. Anatomical and clinical evaluation of the relationship between the temporomandibular joint and occlusion. Journal of Prosthetic Dentsitry. 1997;38:539-51

[24]. Akahane Y, Deguchi T, Hunt NP. Morphology of the temporomandibular joint I skeletal class III symmetrical and asymmetrical cases: a study by cephalometric laminography. Journal of Orthod. 2001;28:119-27

[25]. Enomoto A, et al.: Effects of mastication on mandibular growth evaluated by microcomputed tomography. Eur J Orthod 2010, 32:66-70

[26]. Fangha J, Gedrange T: On the development, morphology and function of the temporomandibular joint in the light of the orofacial system. Ann Anat 2007, 189:314-319.

[27]. Saccucci M, et al.: Do skeletal cephalometric characteristics correlate with condylar volume, surface and shape? A 3D analysis. Head Face Med 2012, 8:15. 